\title{
Light Scattering and Viscometric Study on Polyacrylonitrile in Dimethylformamide, Ethylene Carbonate/Water Mixture, and Aqueous Nitric Acid
}

\author{
Kenji KAMIDE, Yukio MiYAZAKI, and Hidehiko KoBAYASHI* \\ Textile Research Laboratory, Asahi Chemical Industry Company, Ltd., \\ Takatsuki, Osaka 569, Japan \\ *Research and Development Administration, Asahi Chemical Industry Company, Ltd., \\ Hibiya, Tokyo 100, Japan
}

(Received September 12, 1984)

\begin{abstract}
An attempt was made to determine the Flory theta solvents and the unperturbed chain dimension A of polyacrylonitrile (PAN). A sample of PAN, polymerized using redox catalyst and having isotactic triad of $26 \%$ and syndiotactic triad of $24 \%$, was fractionated by successive solution fractionation method to give a series of fractions with the ratio of weight- to numberaverage molecular weight $M_{w} / M_{n}$ of 1.15-1.41. A mixture of ethylene carbonate (EC) and water containing $85 \mathrm{wt} \%$ EC and aq. $55 \mathrm{wt} \%$ nitric acid was identified by the light scattering method to be Flory theta solvents at $25 \mathrm{C}$ whose second virial coefficients were zero. The Mark-HouwinkSakurada (MHS) equations were determined in various solvents. In the theta solvents, the radius of gyration $\left\langle S^{2}\right\rangle_{z}^{1 / 2}$ was proportional to $M_{w}{ }^{1 / 2}$ and the exponent $a$ in MHS equations was always 0.5 . The Flory viscosity parameter $\Phi$ was $2.3 \times 10^{23}$ in DMF and $2.8 \times 10^{23}$ in theta solvents, independent of $M_{w}$. The unperturbed chain dimension parameter A, the conformation parameter $\sigma$ and the characteristic ratio $C_{\infty}$ were determined by thermodynamic and hydrodynamic methods. Both methods gave consistent results. The solvent dependence of these parameters was demonstrated.

KEY WORDS Flory Solvent / Unperturbed Chain Dimension / Polyacrylonitrile / Second Virial Coefficient / Mark-Houwink-Sakurada Equation / Flory viscosity Parameter / Conformation Parameter / Characteristic Ratio /
\end{abstract}

In a previous paper, ${ }^{1}$ we investigated the dilute solution properties of a random acrylonitrile (AN)/methyl acrylate (MA) copolymer with $92 \mathrm{wt} \% \mathrm{AN}$ and found, using the light scattering method, ethylene carbonate (EC) and water containing $82.5 \mathrm{wt} \% \mathrm{EC}$ and a $51 \mathrm{wt} \%$ aqueous nitric acid as a mixture, both to be Flory theta solvents at $25^{\circ} \mathrm{C}$. The effect of polar solvent on molecular properties of the AN/MA copolymer was clarified.

In the past 30 years a number of investigators, including Cleland and Stockmayer, ${ }^{2}$ Krigbaum and Kotliar, ${ }^{3}$ Onyon, ${ }^{4}$ Fujisaki and Kobayashi, ${ }^{5}$ Peebles, ${ }^{6}$ Kamide et al., ${ }^{7}$ and Shibukawa and his coworkers, ${ }^{8}$ have studied the dilute solution properties of polyacrylo- nitrile (PAN) in dimethylformamide (DMF) using light scattering and viscometric methods. These studies on PAN in DMF were clearly prompted by the industrial importance of PAN. Nevertheless, no theta solvent for PAN has been found by thermodynamic methods because of the experimental difficulty in eliminating the fluorescence usually contaminating the scattered light and low solubility of PAN.

Kamide and his collaborators ${ }^{9.10}$ identified some solvents as the theta solvent, though indirectly from the exponent value $a=0.5$ in the Mark-Houwink-Sakurada (MHS) equation:

$$
[\eta]=K_{\mathrm{m}} M^{a}
$$


where $[\eta]$ is the limiting viscosity number, $M$, molecular weight, and $K_{\mathrm{m}}$ and $a$ constants independent of $M$. It is a well established fact $a$ becomes 0.5 in theta solvents. Based on this fact, Kamide et al. found an aqueous EC with $85 \mathrm{wt} \%$ to be a theta solvent at $25 \mathrm{C}$ for a PAN prepared by conventional redox polymerization and $\mathrm{EC}$ itself to be also a theta solvent at $60^{\circ} \mathrm{C}$ for another PAN prepared by gammaray irradiation of urea-canal complex of AN ( $\gamma$-PAN). However, they did not perform direct light scattering measurements of the unperturbed chain dimension of PAN in theta solvents and estimated it indirectly from thermodynamic and hydrodyamic data in non-theta solvents or from hydrodynamic data in an approximately theta solvent.

In this article, we determine theta solvents by light scattering and evaluated the thermodynamic nad hydrodynamic properties of PAN in various solvents including the theta solvents thus obtained.

\section{EXPERIMENTAL}

\section{Sample}

A sample of PAN was prepared in water by the conventional free radical polymerization of acrylonitrile at $55^{\circ} \mathrm{C}$ using ammonium persulfate and ammonium hydrogen sulfite as initiators. The limiting viscosity number $[\eta]$ of this polymer was $210 \mathrm{ml} \mathrm{g}^{-1}$ in DMF at $25^{\circ} \mathrm{C}$ and the viscosity-average molecular weight $M_{v}$ was $1.68 \times 10^{5}$ as calculated from the MHS equation established here (see Table III).

Figure 1 shows a ${ }^{13} \mathrm{C}$ NMR spectrum of the PAN sample in deuterated dimethyl sulfoxide $\left(\right.$ DMSO- $d_{6}$ ). The spectrum was obtained from a JOEL FX 270 Pulse-Fourier Transform NMR spectrometer $(67.80 \mathrm{MHz})$ at $37^{\circ} \mathrm{C}$. The triad tacticity was evaluated according to Inoue and Nishioka's procedure ${ }^{11}$ from methine and cyano carbons, and both gave the same results: isotactic triad $26 \%$; syndiotactic triad, $24 \%$; heterotactic triad $50 \%$. The PAN prepared in this study was isotactic diad of

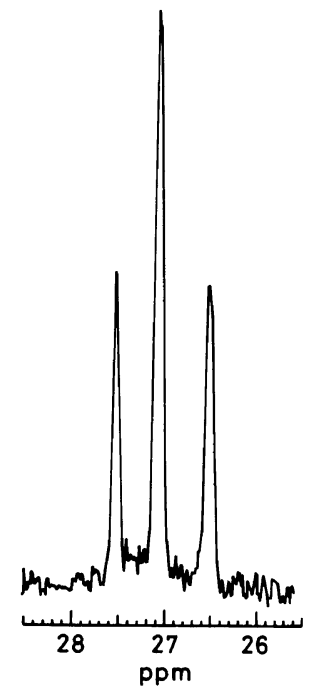

Figure 1. ${ }^{13} \mathrm{C}$ NMR spectrum of the methine carbon of PAN in deuterated dimethyl sulfoxide (DMSO- $d_{6}$ ).

$51 \%$. This value is similar to those reported previously for PANs prepared by redox polymerization. ${ }^{12}$

\section{Solvents}

Reagent grade dimethylformamide (DMF), ethylene carbonate (EC) and analytical chemical grade $70 \mathrm{wt} \%$ aqueous nitric acid, dimethyl sulfoxide (DMSO) and toluene were utilized as received. The polymer, prepared by redox polymerization, contained a catalyst residue, such as $-\mathrm{SO}_{3} \mathrm{H}$, easily ionized in solvent, at the chain ends. The addition of $\mathrm{LiCl}$ reduced both $[\eta]$ and $k^{\prime} .0 .1 \cdot \mathrm{wt} \% \mathrm{LiCl}$ was sufficient to suppress the ionic behavior of PAN solution and bring about a $2 \%$ decrease in $[\eta]$. We added $0.1 \mathrm{wt} \%$ of $\mathrm{LiCl}$ to $\mathrm{DMF}$, in which PAN was dissolved. EC/water mixtures containing 85 and $87.5 \mathrm{wt} \%$ EC (i.e., $w_{\mathrm{e}}=85$ and $87.5 \mathrm{wt}^{\mathrm{o}} \%$ ) were prepared by adding distilled water to $\mathrm{EC}$, and, 55, 60, and $67 \mathrm{wt} \%$ aqueous nitric acid were prepared by adding distilled water to $70 \mathrm{wt} \%$ aqueous nitric acid. To these aqueous nitric acid $500 \mathrm{ppm}$ of urea was added to accelerate the decomposition reaction of nitrous acid and nitrogen oxide (NO) remaining in the nitric acid and prevent 
the decomposition reaction of nitric acid.

\section{Fractionation}

The successive solution fractionation (SSF) was employed using DMSO as solvent and toluene as non-solvent. ${ }^{1}$ A complete liquidliquid phase separation always occurred in PAN solutions of these solvents, and the polymer-lean phase at each step was separated as a fraction. Thus, a $1.0 \mathrm{wt} \%$ solution of PAN sample in DMSO was separated into 18 fractions at $45^{\circ} \mathrm{C}$. Among them, these seven fractions each having a weight-average molecular weight $M_{w}$ from $5.2 \times 10^{4}$ to $5.2 \times 10^{5}$ were used.

\section{Solution Viscosity}

Solution viscosity was measured in DMF $(0.1 \mathrm{wt} \% \mathrm{LiCl}), \mathrm{EC} /$ water mixture $\left(w_{\mathrm{e}}=85\right.$ $\mathrm{wt} \%$ ), and aqueous nitric acid (nitric acid content $w_{n}=55$ and $67 \mathrm{wt} \%$ ) with a modified Ubbelohde suspension type viscometer at $25 \pm 0.01^{\circ} \mathrm{C}$. The polymer was dissolved in $\mathrm{DMF}, \mathrm{EC} /$ water mixture and $55 \mathrm{wt} \%$ aqueous nitric acid at $50^{\circ} \mathrm{C}$ and in $67 \mathrm{wt} \%$ aqueous nitric acid at $20^{\circ} \mathrm{C}$. The polymer in $\mathrm{EC} /$ water mixture was stored at $30^{\circ} \mathrm{C}$.

\section{Light Scattering}

Light scattering measurements were made in DMF, EC/water mixture and aqueous nitric acid. Aqueous nitric acid is a very successful and widely used inorganic solvent for PAN. A light scattering photometer, Union Giken LS-601, and FICA photogoniodiffusiometer, 42000 were used for the first solvent and the last two solvents, respectively.

\section{(a) $D M F$}

The basic procedure for preparing the solution was similar to that in the previous study. ${ }^{1}$ But some improvement were made, such as using a polytetrafluoroethylene membrane filter FP-010 (pore diameter $0.10 \mu \mathrm{m}$ ), manufactured by Sumitomo Denko Co.

The specific refractive index increment $\mathrm{d} \tilde{n}$ / $\mathrm{d} C$ for the PAN in DMF was determined to be $0.078 \mathrm{~cm}^{3} \mathrm{~g}^{-1}$ by a Shimadzu differential refractometer model DR- 4 at $25^{\circ} \mathrm{C}$ at a wave length $\lambda_{0}$ of $633 \mathrm{~nm}$. This value is comparable to $0.087 \mathrm{~cm}^{3} \mathrm{~g}^{-1}\left(\lambda_{0}=436 \mathrm{~nm}\right)$, determined for a redox PAN in DMF without $\mathrm{LiCl}^{7}$

Polarized He-Ne laser light of wave length $\lambda_{0}=633 \mathrm{~nm}$ was used as incident beam and the unpolarized scattering intensity was measured at various angles $\theta$ from 20 to $135^{\circ}$. A spectroscopic analysis of the scattering light from PAN/DMF solution when $\lambda_{0}=633 \mathrm{~nm}$ showed no contamination by fluorescence and no correction of measured intensity for fluorescence, proposed before by Kamide et al., ${ }^{7}$ was made. Calibration of the apparatus was made using benzene (the Rayleigh ratio at $\theta=90^{\circ}, R_{90}=$ $11.84 \times 10^{-6}$ at $\lambda_{0}=633 \mathrm{~nm}^{13}$ ). The data obtained were analyzed according to Zimm's procedure to evaluate the weight-average molecular weight $M_{w}, z$-average radius of gyration $\left\langle S^{2}\right\rangle_{z}^{1 / 2}$ and second virial coefficient $A_{2, \mathrm{~L}}$.

\section{(b) EC/Water Mixture}

The PAN sample was dissolved at $50^{\circ} \mathrm{C}$ in two EC/water mixtures of EC content $w_{\mathrm{e}}=85$ and $87.5 \mathrm{wt} \%$. The preparative procedure for the solution was the same as previously described. ${ }^{1}$ No precipitation was observed in PAN solutions in the EC/water mixture during measurements at $25^{\circ} \mathrm{C}$.

Detailed procedures for the light scattering measurements and analysis of data were the same as those described in the previous paper ${ }^{1}$ for the AN/MA copolymer solution. The approximate value of $M_{w}$, determined in DMF, was assumed for the EC/water mixture, and $\left\langle S^{2}\right\rangle_{z}^{1 / 2}$ and $A_{2, \mathrm{~L}}$ were calculated.

(c) Aqueous Nitric Acid

$\left\langle S^{2}\right\rangle_{z}^{1 / 2}$ of the PAN in aqueous nitric acid $\left(w_{n}=55,60\right.$, and $67 \mathrm{wt}^{\mathrm{o}} \%$ ) was determined, assuming the $M_{w}$ values measured in DMF to be obtainable even in nitric acid. This assumption was partly varied by confirming the constancy of $M_{w}$ of PAN sample before and after dissolving in nitric acid for $3 \mathrm{~h}$. Light scattering for the polymer/inorganic acid system was 
first used by us in study of AN/MA copolymers $^{1}$ and was applied to PAN polymers without serious modification. Great care was taken to ensure that nitric acid in the solution did not decompose and the solution was kept colorless and transparent.

\section{Osmotic Pressure}

The number-average molecular weight $M_{n}$ and second virial coefficient $A_{2.0}$ of the PAN/ DMF system were determined by membrane osmometry by the same manner used for the AN/MA copolymer in DMF.

\section{Adiabatic Compressibility}

The adiabatic compressibility $\beta$ of the solution was calculated by the equation of Laplace.

$$
\beta=1 /\left(\rho v^{2}\right)
$$

Here, $\rho$ and $v$ are the density and sound velocity of the solution, respectively. The ultrasonic velocity was measured with a Pierce type ultrasonic interferometer, employed by Kamide and Saito, ${ }^{14}$ operating at 4.99985 MHz. The temperature of the solution was controlled to $\pm 0.005^{\circ} \mathrm{C}$ or less. $\rho$ of the solution was measured with an Ostwald type pycnometer. Solutions of different concentrations ( $x$ : g-polymer $/ 100 \mathrm{~g}$-solvent) were prepared independently.

The weight of the solvated solvent per gram of polymer $n$ was calculated by the equation of Passynsky. ${ }^{15}$

$$
n=\left(1-\beta / \beta_{\mathrm{s}}\right)(100-x) / x
$$

$\beta_{\mathrm{s}}$ denotes the adiabatic compressibility of the solvent. Equation 3 was derived assuming the polymer and solvent in the solvating region to be incompressible.

\section{RESULTS AND DISCUSSION}

Figure 2a, b, and c shows some typical Zimm plots of a PAN fraction (PAN-4, $M_{w}=$ $\left.15.8 \times 10^{4}\right)$ in $\mathrm{DMF}, 67 \mathrm{wt} \%$ aqueous nitric acid and $\mathrm{EC} /$ water mixture $\left(w_{\mathrm{e}}=85 \mathrm{wt} \%\right)$. No

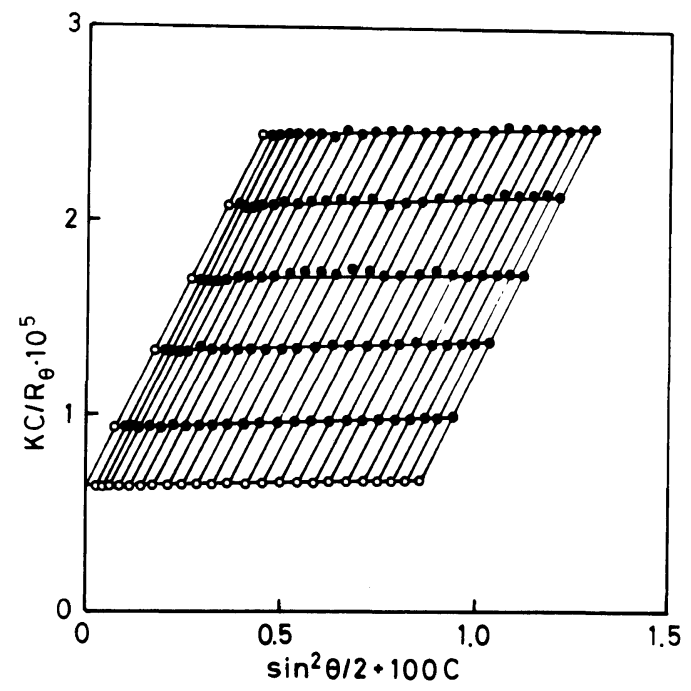

(a)

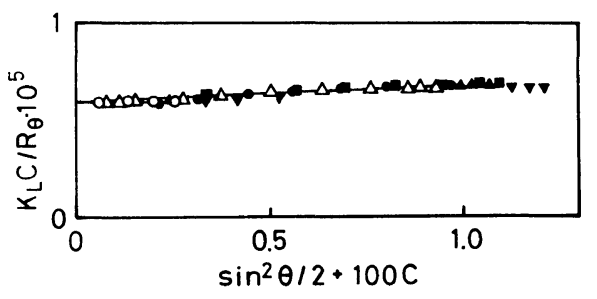

(b)

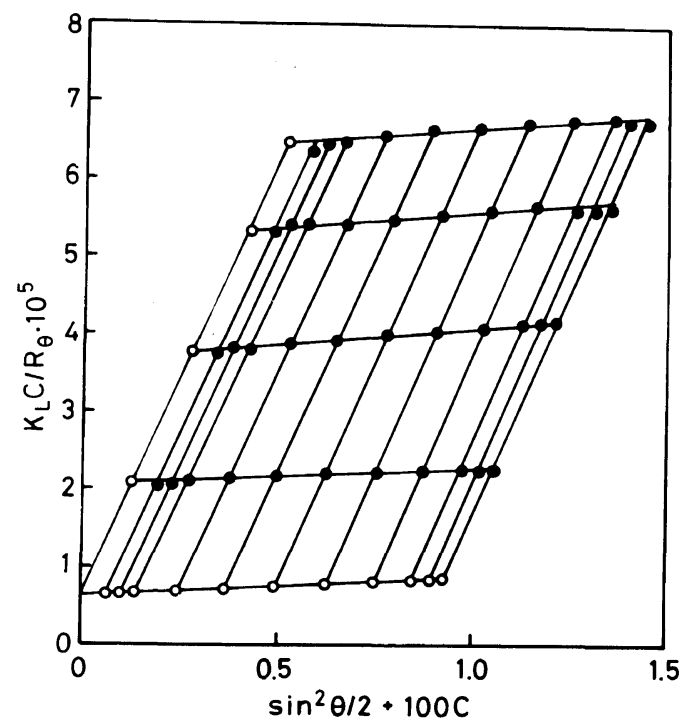

(c)

Figure 2. A typical Zimm plot for PAN-4 at $25 \mathrm{C}$ : (a) in DMF; (b) in the EC/water mixture $\left(w_{\mathrm{e}}=85 \mathrm{wt} \%\right)$; (c) in aqueous nitric acid $\left(w_{\mathrm{n}}=67 \mathrm{wt} \%\right)$. 
Table I. Results of light scattering and osmometry on polyacrylonitrile fractions in $\mathrm{DMF}, 67 \mathrm{wt} \% \mathrm{HNO}_{3}, 85 \mathrm{wt} \% \mathrm{EC}$, and $55 \mathrm{wt} \% \mathrm{HNO}_{3}$ at $25 \mathrm{C}$

\begin{tabular}{|c|c|c|c|c|c|c|c|c|}
\hline \multirow{3}{*}{ Sample } & \multicolumn{6}{|c|}{ Light scattering } & \multirow{2}{*}{\multicolumn{2}{|c|}{$\frac{\text { Osmometry }}{\text { DMF }}$}} \\
\hline & \multicolumn{3}{|c|}{ DMF } & \multirow{2}{*}{$\frac{67 \mathrm{wt} \% \mathrm{HNO}_{3}}{\left\langle S^{2}\right\rangle_{z}^{1 / 2} \times 10^{8}}$} & \multirow{2}{*}{$\frac{85 \mathrm{wt} \% \mathrm{EC}}{\left\langle S^{2}\right\rangle_{z}^{1 / 2} \times 10^{8}}$} & \multirow{2}{*}{$\frac{55 \mathrm{wt} \% \mathrm{HNO}_{3}}{\left\langle S^{2}\right\rangle_{z}^{1 / 2} \times 10^{8}}$} & & \\
\hline & $M_{w^{\prime}} \times 10^{-4}$ & $\left\langle S^{2}\right\rangle_{z}^{1 / 2} \times 10^{8 \mathrm{a}}$ & $A_{2} \times 10^{3 \mathrm{~b}}$ & & & & $M_{n} \times 10^{-4}$ & $A_{2} \times 10^{3}$ \\
\hline PAN-1 & 5.2 & 128 & 2.65 & 142 & 98 & 112 & 3.9 & 1.87 \\
\hline PAN-2 & 7.5 & 153 & 2.45 & 176 & 117 & 135 & 6.2 & 1.64 \\
\hline PAN-3 & 10.7 & 183 & 2.59 & 218 & 140 & 161 & - & - \\
\hline PAN-4 & 15.8 & 236 & 2.55 & 262 & 170 & 196 & 11.2 & 1.83 \\
\hline PAN-5 & 21.5 & 276 & 2.20 & 310 & 198 & 229 & 16.0 & 1.64 \\
\hline PAN-6 & 31.2 & 333 & 2.00 & 395 & 239 & 276 & 27.0 & 1.49 \\
\hline PAN-7 & 52.0 & 453 & 1.80 & 505 & 309 & 356 & - & - \\
\hline
\end{tabular}

a $\mathrm{cm} . \quad$ b $\mathrm{mol} \cdot \mathrm{cm}^{3} \cdot \mathrm{g}^{-2}$.

Table II. Limiting viscosity number $[\eta]$ and Flory viscosity parameter $\Phi$ for polyacrylonitrile fractions in various solvents at $25^{\circ} \mathrm{C}$

\begin{tabular}{|c|c|c|c|c|c|c|c|c|c|}
\hline \multirow{2}{*}{ Sample } & \multirow{2}{*}{$M_{w^{\prime}} \times 10^{4}$} & \multicolumn{2}{|c|}{ DMF } & \multicolumn{2}{|c|}{$67 \mathrm{wt}^{\circ} \% \mathrm{HNO}_{3}$} & \multicolumn{2}{|c|}{$85 \mathrm{wt} \% \mathrm{EC} / \mathrm{W}$} & \multicolumn{2}{|c|}{$55 \mathrm{wt} \% \mathrm{HNO}_{3}$} \\
\hline & & {$[\eta]^{\mathrm{a}}$} & $\Phi^{\mathrm{b}}$ & {$[\eta]$} & $\Phi$ & {$[\eta]$} & $\Phi$ & {$[\eta]$} & $\Phi$ \\
\hline PAN-1 & 5.2 & 90 & 2.13 & 105 & 1.48 & 52 & 2.74 & 82 & 2.90 \\
\hline PAN-2 & 7.5 & 117 & 2.32 & 135 & 1.59 & 62 & 2.76 & 92 & 2.66 \\
\hline PAN-3 & 10.7 & 143 & 2.38 & 165 & 1.62 & 77 & 2.89 & 115 & 2.80 \\
\hline PAN-4 & 15.8 & 192 & 2.20 & 205 & 1.40 & 89 & 2.73 & 132 & 2.64 \\
\hline PAN-5 & 21.5 & 235 & 2.28 & 256 & 1.52 & 101 & 2.66 & 163 & 2.77 \\
\hline PAN-6 & 31.2 & 298 & 2.40 & 304 & 1.41 & 130 & 2.83 & 192 & 2.72 \\
\hline PAN-7 & 52.0 & 445 & 2.38 & 460 & 1.49 & 160 & 2.69 & 256 & 2.81 \\
\hline
\end{tabular}

${ }^{\mathrm{a}} \mathrm{cm}^{3} \cdot \mathrm{g}^{-1}$. b $10^{23} \cdot \mathrm{g}^{-1}$

downward distortion is observed for these plots, suggesting the correction of fluorescence, unavoidably necessary for a PAN/DMF solution without $\mathrm{LiCl}$ at incident light $\lambda_{0} 436$ $\mathrm{nm}$ and $546 \mathrm{~nm}$, not to be needed.

Table I lists $M_{w}, M_{n},\left\langle S^{2}\right\rangle_{z}^{1 / 2}, A_{2, \mathrm{~L}}$ and $A_{2,0}$ for seven PAN fractions in DMF. The table also contains the data for $\left\langle S^{2}\right\rangle_{z}^{1 / 2}$ for the same fractions in 67 and $55 \mathrm{wt} \%$ aqueous nitric acid and $\mathrm{EC} /$ water mixture with $w_{\mathrm{e}}=85 \mathrm{wt} \%$, all at $25^{\circ} \mathrm{C}$. From Table I, it is apparent that the polymolecularity of the fraction covering $M_{w} \times 10^{-4}$ from 5.2 to 52.0 is almost constant, $\left(M_{w} / M_{n}=1.15-1.41\right.$ (average, 1.29)). Separation of a series of fractions of constant polymolecularity is an advantage of
SSF as predicted by theory. ${ }^{16}$ Note that all the polymer samples utilized hitherto in the literature were all prepared by successive precipitation fractionation (SPF) and the polymolecularity of the fractions obtained by SPF depends significantly on $M_{w}$.

Table II shows the limiting viscosity numbers $[\eta]$ in DMF, 67 and $55 \mathrm{wt} \%$ aqueous nitric acid, and EC/water mixture with $w_{\mathrm{e}}=85 \mathrm{wt} \%$.

Figure 3 shows a plot of $\left(K_{\mathrm{L}} C / R_{\theta}\right)_{\theta \rightarrow 0}$ against the polymer concentration $C$ for fraction PAN-4 with $M_{w}=15.8 \times 10^{4}$ in aqueous nitric acid at various $w_{n}$. Here,

$$
\begin{aligned}
K_{\mathrm{L}}= & \left(\left(2 \pi^{2} \tilde{n}_{0}{ }^{2}\right) /\left(\lambda_{0}{ }^{4} N_{\mathrm{A}}\right)(\mathrm{d} \tilde{n} / \mathrm{d} C)_{w_{\mathrm{e}}}{ }^{2}\right) \\
& \left(1+\xi_{\mathrm{a}}\left(\mathrm{d} \tilde{n}_{0} / \mathrm{d} w_{\mathrm{e}}\right) /(\mathrm{d} \tilde{n} / \mathrm{d} C)_{w_{\mathrm{e}}}\right)^{2} ;
\end{aligned}
$$




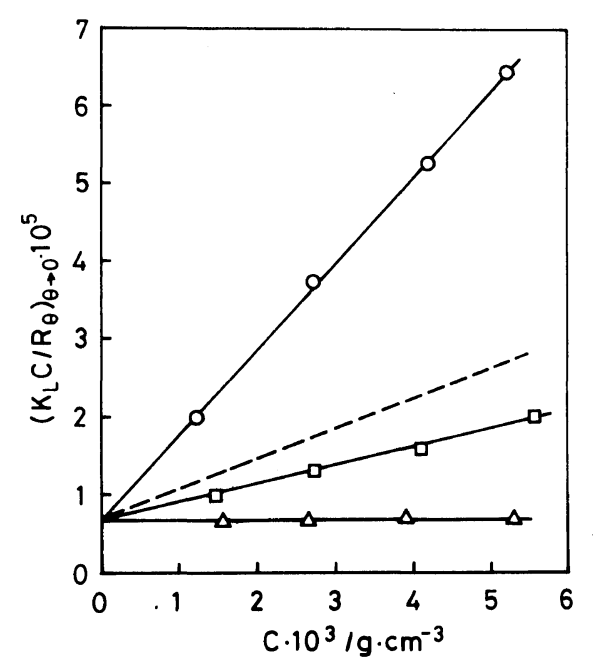

Figure 3. Plot of $\left(K_{\mathrm{L}} \mathrm{C} / R_{\theta}\right)_{\theta \rightarrow 0}$ versus polymer concentration $C$ for PAN-4 in aqueous nitric acid at $25^{\circ} \mathrm{C}$ : $O, w_{\mathrm{n}}=67 \mathrm{wt}^{\circ} \%, \square, w_{\mathrm{n}}=60 \mathrm{wt} \% ; \quad \triangle, w_{\mathrm{n}}=55 \mathrm{wt} \%$; broken line, in DMF at $25^{\circ} \mathrm{C}$.

$(\mathrm{d} \tilde{n} / \mathrm{d} C)_{w_{\mathrm{e}}}$ is the refractive index increment of the polymer solution at constant composition $\left(0.114 \mathrm{~cm}^{3} \mathrm{~g}^{-1}\right.$ at $\left.w_{\mathrm{e}}=85 \mathrm{wt} \%\right), \mathrm{d} \tilde{n}_{0} / \mathrm{d} w_{\mathrm{e}}$, the refractive index increment of the binary mixture $\left(0.087 \mathrm{~cm}^{3} / \mathrm{g}\right), \xi_{\mathrm{a}}$, the preferential adsorption parameter $\left(\equiv-d w_{\mathrm{e}} / \mathrm{d} C\right)^{17} ; \tilde{n}_{0}$, refractive index of the solvent, and $N_{\mathrm{A}}$, Avogadro's constant. The value of $K_{\mathrm{L}}$ was evaluated by substituting the experimental values of $\left(C / R_{\theta}\right)_{\substack{\theta \rightarrow 0 \\ c \rightarrow 0}}^{-1}$ for aqueous nitric acid and $M_{w}$ obtained in DMF into the relation $K_{\mathrm{L}}=$ $\left(1 / M_{w}\right)\left(C / R_{\theta}\right)_{\substack{\boldsymbol{c} \rightarrow 0 \\ c \rightarrow 0}}^{-1} . K_{\mathrm{L}} \times 10^{17}$ was 1.21 and 1.14 for $w_{\mathrm{n}}=55$ and $67 \mathrm{wt} \%$, respectively. The slope of the plot, equal to $2 A_{2, \mathrm{~L}}$, becomes zero at $w_{\mathrm{n}}=55 \mathrm{wt} \%$ with an estimated uncertainty of $\pm 1 \mathrm{wt} \%$ for $w_{\mathrm{n}}$. That is, $55 \mathrm{wt} \%$ aqueous nitric acid can be regarded as a Flory theta solvent for PAN. Comparable results have been obtained for AN/MA copolymer ${ }^{1}$ a $51 \mathrm{wt} \%$ nitric acid is a Flory theta solvent.

Figure 4 shows a plot of $\left(K_{\mathrm{L}} C / R_{\theta}\right)_{\theta \rightarrow 0}$ against $C$ for fraction PAN-4 with $M_{w}=$ $15.8 \times 10^{4}$ in various $\mathrm{EC} /$ water mixtures. Here, $K_{\mathrm{L}}$ was evaluated from the experimental values of $\left(C / R_{\theta}\right)_{c \rightarrow 0}$ for the $\mathrm{EC} /$ water mix-

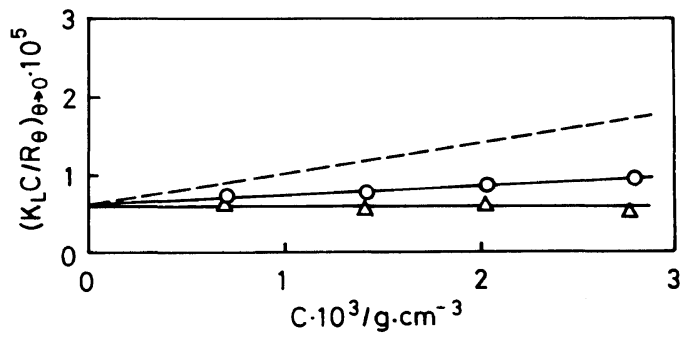

Figure 4. Plot of $\left(K_{\mathrm{L}} C / R_{\theta}\right)_{\theta \rightarrow 0}$ versus polymer concentration $C$ for PAN-4 in EC/water mixture at $25^{\circ} \mathrm{C}$ : $\mathrm{O}, w_{\mathrm{e}}=87.5 \mathrm{wt} \% ; \triangle w_{\mathrm{e}}=85 \mathrm{wt} \%$; broken line, in $\mathrm{DMF}$ at $25^{\circ} \mathrm{C}$.

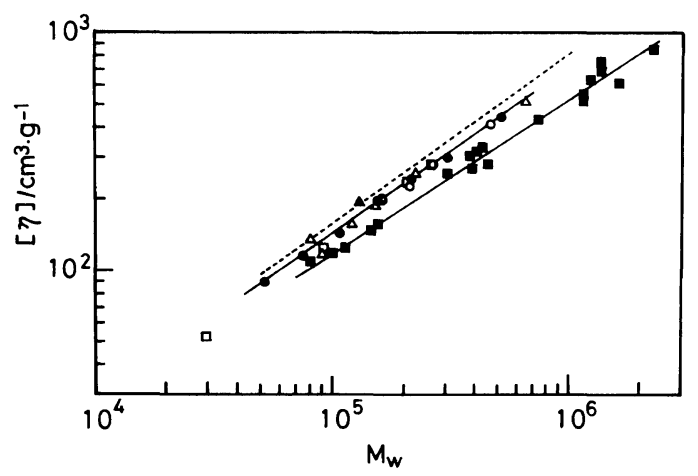

Figure 5. Log-log plots of limiting viscosity number $[\eta]$ versus weight-average molecular weight $M_{w}$ for PAN in DMF at $25^{\circ} \mathrm{C}$ : $\square$, Cleand and Stockmayer ${ }^{2} ;$ Krigbaum and $\mathrm{Kotliar}^{3} ; \triangle$, Onyon ${ }^{4} ; \mathbf{\square}$, Peebles ${ }^{6} ; 0$, Shibukawa et al..$^{8}$, dotted line, eq $(\mathrm{e}-1)^{\prime} ; \mathbf{O}$, this work.

ture and $M_{w}$ value obtained in DMF. The value of $K_{\mathrm{L}}$ so determined was $\left(1.03 \times 10^{-7}\right)$ for $\mathrm{EC} /$ water mixtures with $w_{\mathrm{e}}=85-87.5$ $\mathrm{wt} \%$. The slope of the plot reduced to zero in $w_{\mathrm{e}}=85 \mathrm{wt} \%$ at $25^{\circ} \mathrm{C}$, which is another theta solvent for PAN. It was confirmed that the solutions of $\mathrm{PAN}$ in $55 \mathrm{wt} \%$ aqueous nitric acid and EC/water mixture $\left(w_{\mathrm{e}}=\right.$ $85 \mathrm{wt} \%$ ) were very stable and no indication of aggregation or crystallization was detected at $25^{\circ} \mathrm{C}$ within $6 \times 10^{3} \mathrm{~min}$. The reliability of the Kamide et al. estimation of the theta solvent $\left(\mathrm{EC} /\right.$ water with $w_{\mathrm{e}}=85 \mathrm{wt} \%$ at $\left.26^{\circ} \mathrm{C}\right)$ for redox PAN by the hydrodynamic approach is definitely confirmed. In Figures 3 and 4 the $\left(K C / R_{\theta}\right)_{\theta \rightarrow 0} v s . C$ plot for the same fraction in DMF is shown by the broken line. 
Figure 5 shows the plots of $\log [\eta]$ against $\log M_{w}$ for PAN in DMF constructed from the present and literature data. The latter were obtained from the original data, with correction made from the temperature effect on [ $\eta$, when necessary. $M_{w}$ values of these data were obtained by fluorescence correction in the light scattering experiment $(\lambda=436$ and $546 \mathrm{~nm}$ ) except for those of Shibukawa et al. ${ }^{8}$ The data points of Cleland and Stockmayer, ${ }^{2}$ Krigbaum and Kotliar, ${ }^{3}$ Onyon $^{4}$ and Shibukawa et $a .^{8}$ can be reasonably expressed by the MHS equation: $[\eta]=0.052 M_{w}{ }^{0.69}$ established in this study. In contrast Peebles' data ${ }^{6}$ deviates to the higher $M_{w}$ side for the same [ $\eta$ ]. Peebles used $0.5 \%$ Cornell Standared Polystyrene in toluene for the instrument calibration, but we, Cleland and Stockmayer, ${ }^{2}$ Onyon, ${ }^{4}$ Shibukawa et al. ${ }^{8}$ used benzene. The significant difference in $\log -\log$ plot of $[\eta]$ and $M_{w}$ between Peebles and others may thus be explained by the differences in the standard materials used for the instrumental calibration. Here, the only exception is the case of Krigbaum and Kotliar, ${ }^{3}$ who used the literature value of turbidity, $\lambda_{0}=436 \mathrm{~nm}$ ( $\tau=$ $3.50 \times 10^{-3} \mathrm{~cm}^{-1}$ ) for $0.5 \%$ Cornell Standard Polystyrene in toluene, although they actually measured at $546 \mathrm{~nm}$.

Figure $6 \mathrm{a}$ and $\mathrm{b}$ shows $\log -\log$ plots of $[\eta] v s$. $M_{w}$ for the PAN and AN/MA copolymer in $\mathrm{DMF}, \mathrm{EC} /$ water mixtures and aqueous nitric acids. We carefully reexamined $\mathrm{d} \tilde{n} / \mathrm{d} C$ for $\mathrm{AN} / \mathrm{MA}$ copolymer in $\mathrm{DMF}$ at $25^{\circ} \mathrm{C}$ and reached the conclusion that the value of $\mathrm{d} \tilde{n} / \mathrm{d} C$ $\left(0.77 \mathrm{~cm}^{3} \mathrm{~g}^{-1}\right)$ in the previous paper ${ }^{1}$ is some $3 \%$ underestimated $\left(0.079 \mathrm{~cm}^{3} \mathrm{~g}^{-1}\right)$. Accordingly, the $M_{w}$ values in the literature ${ }^{1}$ are overestimated by $6 \%$ and the $M_{w}$ values cited for AN/MA copolymer have been corrected in this paper. The EC/water mixture with $w_{\mathrm{e}}=$ $82.5 \mathrm{wt} \%$ and aqueous nitric acid with $w_{\mathrm{n}}=$ $51 \mathrm{wt} \%$ at $25^{\circ} \mathrm{C}$ was found to consist of theta solvents for the AN/MA copolymer (with $92 \pm 0.5 \mathrm{wt} \%$ in $\mathrm{AN}$ ) in the previous paper. ${ }^{1}$ The parameter $K_{\mathrm{m}}$ and $a$ in the MHS

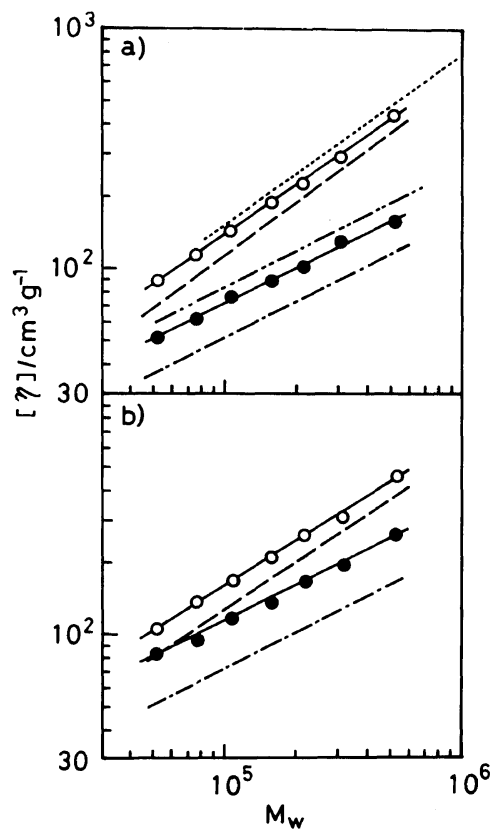

Figure 6. Log-log plots of limiting viscosity number [ $\eta$ ] versus weight-average molecular weight $M_{w}$ for PAN at $25^{\circ} \mathrm{C}$ : a) $O$, in $\mathrm{DMF}$; $\bigcirc$, in $\mathrm{EC} /$ water mixture $\left(w_{\mathrm{e}}=85 \mathrm{wt} \%\right)$; dotted line, PAN in $\mathrm{DMF}^{7}$; broken line, the AN/MA copolymer in $\mathrm{DMF}^{1}$; dot-dash line, the AN/MA copolymer in EC/water mixture $\left(w_{\mathrm{e}}=82.5\right.$ wt $\%)^{1}$; dot-dot-dash line, PAN in EC/water mixture $\left(w_{\mathrm{e}}=85 \mathrm{wt} \%\right)^{9}$. b) $\bigcirc$, in $67 \mathrm{wt} \%$ aqueous nitric acid; $\bigcirc$, in $55 \mathrm{wt} \%$ aqueous nitric acid; broken line, the AN/MA copolymer in $67 \mathrm{wt} \%$ aqueous nitric acid ${ }^{1}$; dot-dash line, the AN/MA copolymer in $51 \mathrm{wt} \%$ aqueous nitric acid. ${ }^{1}$

Table III. $K_{\mathrm{m}}$ and $a$ in Mark-Houwink-Sakurada equations and $K_{\gamma}$ and $\gamma$ in relations between $\left\langle S^{2}\right\rangle_{z}^{1 / 2}$ and $M_{w}$ for PAN in various solvents at $25^{\circ} \mathrm{C}$

\begin{tabular}{lllll}
\hline \multicolumn{1}{c}{ Solvent } & \multicolumn{1}{c}{$K_{\mathrm{m}}$} & \multicolumn{1}{c}{$a$} & $K_{\gamma} \times 10^{8}$ & $\gamma$ \\
\hline $\mathrm{DMF}$ & 0.0520 & $0.69_{0}$ & 0.317 & $0.55_{1}$ \\
$85 \mathrm{wt} \% \mathrm{EC} / \mathrm{W}$ & 0.256 & $0.49_{0}$ & 0.431 & $0.50_{0}$ \\
$55 \mathrm{wt} \% \mathrm{HNO}_{3}$ & 0.342 & $0.50_{1}$ & 0.480 & $0.50_{2}$ \\
$67 \mathrm{wt} \% \mathrm{HNO}_{3}$ & 0.122 & $0.62_{2}$ & 0.359 & $0.55_{2}$ \\
\hline
\end{tabular}

equation (eq 1) were evaluated by the leastsquares method and the results are summarized in Table III.

The MHS parameters in Table III can be corrected for the polydispersity of the PAN samples $\left(M_{w} / M_{n}=1.15-1.41\right.$ (average, 1.29)) 
assuming the Schulz-Zimm distribution of molecular weight. The results are as follows:

$$
\begin{aligned}
& {[\eta]=0.0533 M^{0.69} \text { in DMF at } 25^{\circ} \mathrm{C}} \\
& {[\eta]=0.126 M^{0.62}} \\
& \text { in } 67 \mathrm{wt} \% \text { nitric acid at } 25^{\circ} \mathrm{C} \\
& {[\eta]=0.263 M^{0.49}} \\
& \text { in } \mathrm{EC} / \text { water mixture }\left(w_{\mathrm{e}}=85 \mathrm{wt} \%\right) \\
& \text { at } 25^{\circ} \mathrm{C}
\end{aligned}
$$

and

$$
\begin{aligned}
& {[\eta]=0.351 M^{0.50}} \\
& \text { in } 55 \mathrm{wt} \% \text { nitric acid at } 25^{\circ} \mathrm{C}
\end{aligned}
$$

Kamide et $a .^{7}$ established the following MHS equations

$$
\begin{aligned}
& {[\eta]=0.0466 M_{w}^{0.71}} \\
& \left(5 \times 10^{4}<M_{w}<1 \times 10^{6}, 36 \text { samples }\right)
\end{aligned}
$$

for PAN, prepared by conventional redox polymerization, in $\mathrm{DMF}$ at $20^{\circ} \mathrm{C}$ and

$$
\begin{aligned}
& {[\eta]=0.0429 M_{w^{*}}^{0.71}} \\
& \left(9.3 \times 10^{4}<M_{w}<1 \times 10^{6}, 11 \text { samples }\right)(\mathrm{e}-2)
\end{aligned}
$$

for PAN, prepared by non-redox, precipitation polymerization, in $\mathrm{DMF}$ at $20^{\circ} \mathrm{C}$.

Equation e- 1 can be converted to the MHS equation in $\mathrm{DMF}$ with $\mathrm{LiCl}(0.1 \mathrm{wt} \%)$ at $25^{\circ} \mathrm{C}$

$$
[\eta]=0.0444 M_{w^{\prime}}^{0.712} \quad(\mathrm{e}-1)^{\prime}
$$

and is shown in Figure 6a as the dotted line. Here, the effect of $\mathrm{LiCl}$ in DMF on $[\eta]$, as observed in this study, and temperature on $K_{\mathrm{m}}$ and $a$ in eq 1 , obtained by Fujisaki and Kobayashi ${ }^{18}$ for PAN/DMF system, was taken into consideration. $K_{\mathrm{m}}$ in eq $(\mathrm{e}-1)^{\prime}$ is some $10 \%$ smaller and $a$ in eq $(\mathrm{e}-1)^{\prime}$ is 0.02 larger than those obtained in this study.

The values of the exponent $a$ in the two solvent mixtures are as expected $0.5 \pm 0.01$ (see eq $\mathrm{c}$ and $\mathrm{d}$ ). Hence, we can conclude from the light scattering and solution viscosity measurements that $\mathrm{EC} /$ water $\left(w_{\mathrm{e}}=85 \mathrm{wt} \%\right)$ and 55 $\mathrm{wt} \%$ aqueous nitric acid are Flory theta solvents for redox PAN with isotactic triad $26 \%$, syndiotactic triad $24 \%$, and heterotactic $\operatorname{triad} 50 \%$.

Kamide et al. ${ }^{9}$ showed that the following MHS equation

$$
[\eta]=0.282 M_{v}^{0.50}
$$

holds for redox PAN in EC/water mixture with $w_{\mathrm{e}}=85 \mathrm{wt} \%$ at $26^{\circ} \mathrm{C}$, where $M_{v}$ was calculated using e-1. Equation $\mathrm{f}$ is shown in Figure $6 \mathrm{a}$ as the dot-dot-dash line. The significant difference in $K_{\mathrm{m}}$ between eq $\mathrm{f}$ and that established here in EC/water $\left(w_{\mathrm{e}}=85 \mathrm{wt} \%\right)$ can be attributed to the experimental uncertainty of correction for fluorescence used in determining $M_{w}$. Using the experimental data for the effects of $\mathrm{LiCl}$ and temperature on $[\eta]$ in DMF, we can reconstruct two MHS equations for PAN in EC/water $\left(w_{\mathrm{e}}=85 \mathrm{wt} \%\right)$ at $30^{\circ} \mathrm{C}$ and $35^{\circ} \mathrm{C}$ in ref 9 and estimate the MHS equation by extrapolating the above two eq to $a=0.50$ in the form,

$$
[\eta]=0.266 m_{v}^{0.50} \text { at } 29.3^{\circ} \mathrm{C}
$$

Equation $\mathrm{g}$ is very similar to that established in this article, although temperature is about $4{ }^{\circ} \mathrm{C}$ higher (see Appendix).

Kamide et al. ${ }^{10}$ have pointed out that for PAN polymerized by $\gamma$-ray irradiation of urea canal complex at $-78^{\circ} \mathrm{C}(\gamma$-PAN $)$ the exponent $a$ becomes 0.50 in $\mathrm{EC}$ at $60^{\circ} \mathrm{C}$, and $\gamma$ PAN has $75 \%$ isotacticity. That is, the Flory theta temperature of PAN varies with the stereoregularity of the polymer.

[ $\eta]$ at constant $M_{w}$ in $67 \mathrm{wt} \%$ aqueous nitric acid is larger than that in DMF, but $a$ in the former solvent is slightly smaller than that in the latter. Interestingly, $[\eta]$ values at constant $M_{w}$ in two theta solvents differ from each other: $[\eta]$ in $55 \mathrm{wt} \%$ aqueous nitric acid is larger than $[\eta]$ in EC/water mixture with $w_{\mathrm{e}}=85 \mathrm{wt} \%$. This indicates that the dissolved state, including the unperturbed chain dimension and the degree of solvation (i.e., the specific interaction between the functional group $\mathrm{CN}$ in the polymer and solvent), 


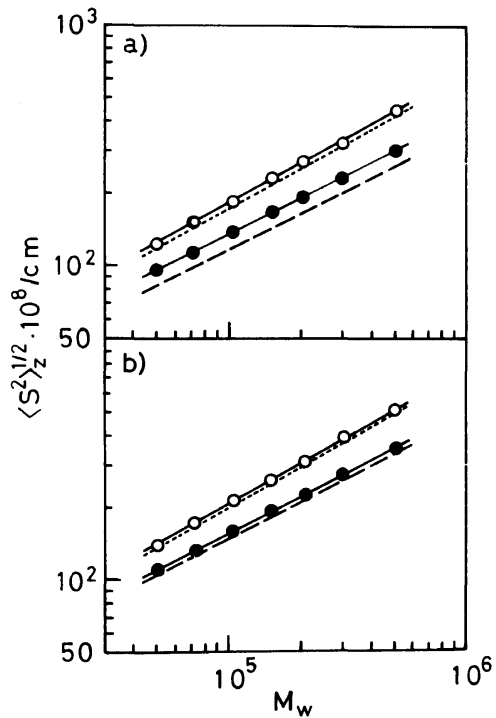

Figure 7. Plots of the radius of gyration $\left\langle S^{2}\right\rangle_{z}^{1 / 2}$ as a function of weight-average molecular weight $M_{w}$ for $\mathrm{PAN}$ at $25^{\circ} \mathrm{C}$ : a) $\mathrm{O}$, in $\mathrm{DMF}$; $\bigcirc$, in the $\mathrm{EC} /$ water mixture $\left(w_{\mathrm{e}}=85 \mathrm{wt} \%\right)$; dotted line, the AN/MA copolymer in $\mathrm{DMF}^{1}$; broken line, the $\mathrm{AN} / \mathrm{MA}$ copolymer in the $\mathrm{EC} /$ water mixture $\left.\left(w_{\mathrm{e}}=82.5 \mathrm{wt} \%\right){ }^{1} \mathrm{~b}\right) \mathrm{O}$, in aqueous nitric acid $\left(w_{\mathrm{n}}=67 \mathrm{wt} \%\right) ; 0$, in aqueous nitric acid $\left(w_{\mathrm{n}}=55 \mathrm{wt} \%\right)$; dotted line, the AN/MA copolymer in aqueous nitric acid $\left(w_{\mathrm{n}}=67 \mathrm{wt} \%\right)$; broken line, the $\mathrm{AN} /$ MA copolymer in aqueous nitric acid $\left(w_{\mathrm{n}}=51 \mathrm{wt} \%\right)^{1}$

varies with the nature of the theta solvent.

Figure 7 shows the molecular weight dependence of $\left\langle S^{2}\right\rangle_{z}^{1 / 2}$ for the PAN polymer in various solvents at $25^{\circ} \mathrm{C}$. The data for the AN/MA copolymer, obtained in the previous paper, ${ }^{1}$ are shown by the dotted and broken lines. $\left\langle S^{2}\right\rangle_{z}^{1 / 2}$ of PAN is larger than that of AN/MA copolymer, when both polymers with constant $M_{w}$ are dissolved in the same solvent. The above finding was observed for both DMF and all other solvents investigated. $\left\langle S^{2}\right\rangle_{z}^{1 / 2}$ is empirically related to $M_{w}$ by

$$
\left\langle S^{2}\right\rangle_{z}^{1 / 2}=K_{\gamma} M_{w}^{\gamma}
$$

The parameters $K_{\gamma}$ and $\gamma$ in eq 4 for PAN solution were determined by the least-squares method and are summarized in Table III. If the partially free draining effect is neglected, the following relation

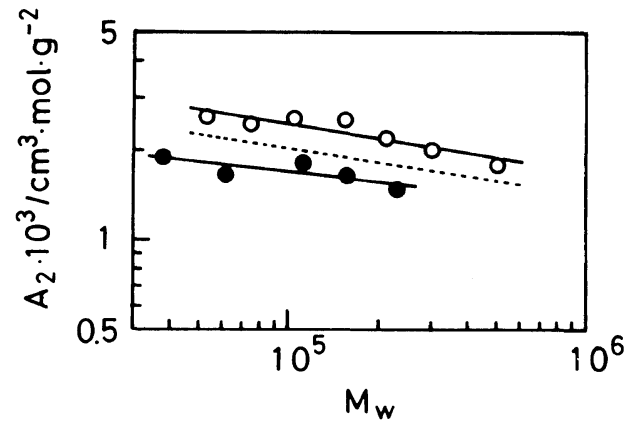

Figure 8. Molecular weight dependence of the second virial coefficient $A_{2}$ for PAN in DMF at $25^{\circ} \mathrm{C}: \bigcirc, A_{2, \mathrm{~L}}$ by light scattering; $O, A_{2.0}$ by osmometry; dotted line, $A_{2, \mathrm{~L}}$ by light scattering for the AN/MA copolymer in DMF. ${ }^{1}$

$$
\gamma=(1+a) / 3
$$

holds between $a$ eq 1 and $\gamma$ in eq 4 . The $\gamma$ values calculated by eq 5 from the experimental $a$ (0.69 and 0.62) in DMF and $67 \mathrm{wt} \%$ nitric acid are 0.56 and 0.54 , respectively, both in farily good agreement with the experimental values ( 0.55 for both solvents). The PAN polymer, like the AN/MA copolymer, behaves as a gaussian chain in Flory theta solvents and PAN expands more in $55 \mathrm{wt} \%$ aqueous nitric acid than in the EC/water mixture $\left(w_{\mathrm{e}}=85\right.$ $\mathrm{wt} \%$ ).

Figure 8 shows the molecular weight dependence of $A_{2}$, determined by light scattering (open circles) and membrane osmometry (closed circles) for PAN in DMF at $25^{\circ} \mathrm{C}$. The empirical relations derived are as follows.

$A_{2 . \mathrm{L}}=1.68 \times 10^{-2} M_{w}{ }^{-0.17}$ in DMF at $25^{\circ} \mathrm{C}$

$A_{2.0}=4.80 \times 10^{-3} M_{2}^{-0.09}$ in DMF at $25^{\circ} \mathrm{C}$

When the molecular weight dependence of $A_{2}$ and the ratio $A_{2} M_{w} /[\eta]$ can be semi-empirically expressed respectively as

$$
A_{2}=K_{v} M_{w}^{-v}
$$

and

$$
A_{2} M_{w} /[\eta]=K_{\varepsilon} M_{w}{ }^{\varepsilon}
$$


$v$ in eq 6 is related to $a$ and $\varepsilon$ by the relation

$$
v=1-a-\varepsilon
$$

Substituting the experimental values of $a(0.69)$ and $\varepsilon(0.15)$, both obtained in DMF, into eq 8 , we obtain $v=0.16$, which is comparable to the experimental value $v(0.17)$. This shows sufficient experimental accuracy.

Equation $\mathrm{h}$ differs somewhat from the relation $^{7}$

$$
A_{2, \mathrm{~L}}=4.94 \times 10^{-2} M_{w}{ }^{-0.29} \text { in DMF at } 20^{\circ} \mathrm{C}
$$

established in the previous paper ${ }^{7}$ for the PAN-DMF system, to which no $\mathrm{LiCl}$ was added and the fluorescence contaminating the scattered light was eliminated by procedure described elsewhere. ${ }^{7}$ The figure shows the molecular weight dependence of $A_{2 . \mathrm{L}}$ for the AN/MA copolymer in DMF.

The values of Flory's viscosity parameter,

$$
\Phi \equiv[\eta] M_{w} q_{w, z} / 6^{3 / 2}\left\langle S^{2}\right\rangle_{z}^{3 / 2}
$$

( $q_{w, z}$ is a correction factor for polydispersity), was calculated for PAN in DMF, 67 and 55 $\mathrm{wt} \%$ aqueous nitric acid, and the EC/water mixture with $w_{\mathrm{e}}=85 \mathrm{wt} \%$, all at $25^{\circ} \mathrm{C} . q_{w, z}$ was calculated assuming the Schulz-Zimm molecular weight distribution for the fractions. The $\Phi$ values in aqueous nitric acid and EC/water mixture were calculated using the $M_{w}$ values obtained in DMF. It is obvious that the $\Phi$ values are almost constant, averaging $(2.3 \pm$ $0.1) \times 10^{23},(1.5 \pm 0.1) \times 10^{23}$, and $(2.8 \pm 0.1) \times$ $10^{23}$ for DMF, $67 \mathrm{wt} \%$ aqueous nitric acid and two theta solvents, and the last value is almost equivalent to the theoretical value. The $\Phi$ values, except for $67 \mathrm{wt} \%$ aqueous nitric acid, are comparable to those obtained for flexible polymer in good and theta solvents. Note that the $\Phi$ values for the $\mathrm{AN} /$ MA copolymer in $51 \mathrm{wt} \%$ aqueous nitric acid (theta solvent) was only $70 \%$ of the theoretical value $\left(2.87 \times 10^{23}\right)$. The $\Phi$ values for PAN in $67 \mathrm{wt} \%$ aqueous nitric acid are unusually small for reasons not completely understood.
The unperturbed chain dimension

$$
A=\left(\left\langle R^{2}\right\rangle_{0} / M\right)^{1 / 2},
$$

$\left[\left\langle R^{2}\right\rangle_{0}^{1 / 2}\right.$ is the mean-square end-to-end distance in the unperturbed state] was evaluated by the following method:

\section{Method $2 A$}

Measurements of $\left\langle S^{2}\right\rangle_{z}^{1 / 2}$ of a polymer in Flory theta solvent allow $A$ to be determined from

$$
A=6^{1 / 2}\left(\left\langle S^{2}\right\rangle_{0} / M\right)^{1 / 2}
$$

where the subscript zero indicates the unperturbed state.

\section{Method 2C (Baumann Plot) ${ }^{19}$}

Using $\left\langle S^{2}\right\rangle_{z}^{1 / 2}$ of a polymer in a non-theta solvent, we can evaluate $A$ by the relation,

$$
\left(\left\langle S^{2}\right\rangle / M\right)^{3 / 2}=A^{3} / 6^{3 / 2}+\left(1 / 4 \pi^{3 / 2}\right) B M^{1 / 2}(10)
$$

Here, $B$ is a long-range interaction parameter. Method $2 E$ (Stockmayer-Fixman Plot $)^{20}$

$$
[\eta] / M^{1 / 2}=K+2(3 / 2 \pi)^{3 / 2} \Phi_{0}(\infty) B M^{1 / 2}
$$

with

$$
K=\Phi_{0}(\infty) A^{3}
$$

Method $2 F$ (Kamide et al. Plot $)^{21}$

$$
\begin{aligned}
& -\log k_{\mathrm{m}}+\log \left[1+2\left\{(a-0.5)^{-1}-2\right\}^{-1}\right] \\
& =-\log K+(a-0.5) \log M_{0}
\end{aligned}
$$

$M_{0}$ can be approximated with a geometric average of the lower- and upper-limit of $M$.

$\left\langle S^{2}\right\rangle_{0}^{1 / 2}$ or $\left\langle S^{2}\right\rangle^{1 / 2}$ in eq 9 and 10 is the weight-average quantity, which is converted from the $z$-average quantity, using the experimental values of $M_{w} / M_{n}$ and assuming the Schulz-Zimm distribution for each fraction.

Method 2A was applied to PAN in two theta solvents and the results are listed in Table IV. The A value in the EC/water mixture with $w_{\mathrm{e}}$ of $85 \mathrm{wt} \%$ is about $15 \%$ smaller than that in $55 \mathrm{wt} \%$ aqueous nitric acid. A similar difference was observed for the AN/MA copolymer. 
Figures 9 and 10 show the Baumann and Stockmayer and Fixman plots for PAN in various solvents. Both plots are well represented by straight lines, even at the highest molecular weight fraction. The A values obtained from the intercept are summarized in Table IV. Table IV also includes the A values evaluated by method $2 \mathrm{~F}$. In applying methods $2 \mathrm{E}$ and $2 \mathrm{~F}$, the experimental $\Phi$ values were corrected for the excluded volume effect $\left(\Phi / \alpha_{\mathrm{s}}{ }^{-0.57}\right)$ and taken to be $\Phi_{0}(\infty)$ for $67 \mathrm{wt} \%$ aqueous nitric acid and the DMF solution. Here, $\alpha_{\mathrm{s}}$ was estimated conventionally from the ratio

$$
\left\langle S^{2}\right\rangle^{1 / 2} /\left(A(\operatorname{method} 2 \mathrm{C}) / 6^{1 / 2} \mathrm{M}^{1 / 2}\right) \text {. }
$$

Table IV indicates all the methods including thermodynamic and hydrodynamic approaches to yield almost the same $A$ values in each solvent.

The conformation parameter $\sigma$ and characteristic ratio $C_{\infty}$ are expressed by

$$
\begin{gathered}
\sigma=A / A_{\mathrm{f}} \\
C_{\infty}=A^{2} M_{\mathrm{b}} / l^{2}
\end{gathered}
$$

where $A_{\mathrm{f}}$ is the $A$ of a hypothetical chain with free internal rotation, $M_{\mathrm{b}}$ is the mean molecular weight per skeletal bond (26.5), and $l$ is the mean bond length $\left(1.54 \times 10^{-8} \mathrm{~cm}\right)$. The values of $\sigma$ and $C_{\infty}$ calculated using the most probable $A$ values are tabulated in the seventh and eighth columns of Table IV.

The most probable $A$ is the average of values obtained by thermodynamic approaches (method 2A and 2C) and is given in the sixth column of Table IV. This table also gives $B$ values estimated from the slopes of the plots in Figures 9 and 10. The $B$ values by method 2C (thermodynamic approach) are in fairly good agreement with those by method $2 \mathrm{E}$

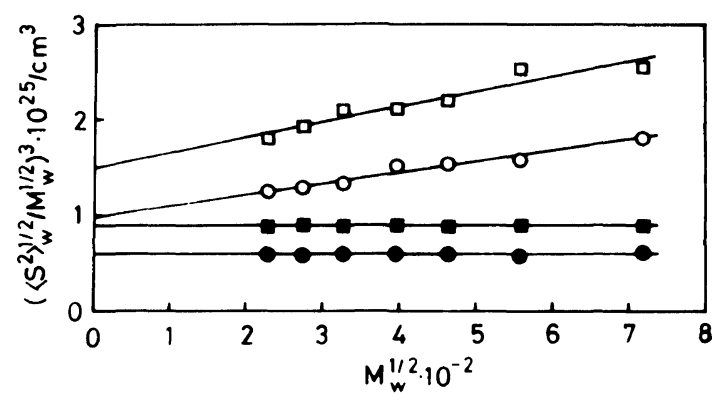

Figure 9. Baumann plot (method 2C) for PAN at $25^{\circ} \mathrm{C}$ : $\bigcirc$, DMF; $\square$, aqueous nitric acid $\left(w_{\mathrm{n}}=67 \mathrm{wt} \%\right)$; - EC/water mixture $\left(w_{\mathrm{e}}=85 \mathrm{wt} \%\right)$; , aqueous nitric acid $\left(w_{\mathrm{n}}=55 \mathrm{wt} \%\right)$.

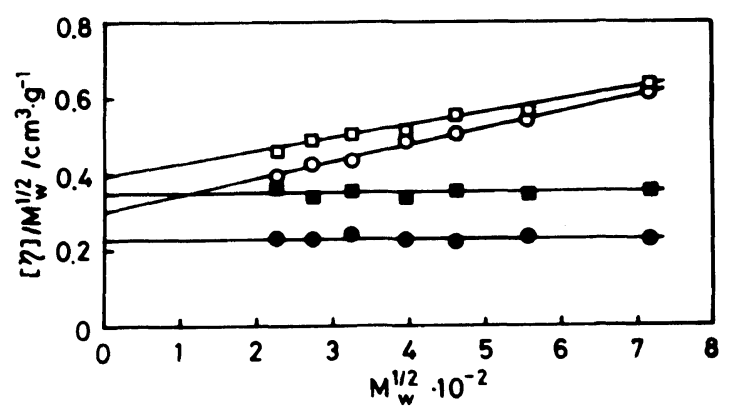

Figure 10. Stockmayer-Fixman plot (method 2E) for PAN at $25^{\circ} \mathrm{C}$ : Marks have the same meaning as in Figure 9.

Table IV. Unperturbed chain dimension $A$, long-range interaction parameter $B$,

\begin{tabular}{|c|c|c|c|c|c|c|c|c|c|}
\hline \multirow{2}{*}{ Solvent } & \multicolumn{5}{|c|}{$A \times 10^{8} / \mathrm{cm}$} & \multirow{2}{*}{$\sigma$} & \multirow{2}{*}{$C_{\infty}$} & \multicolumn{2}{|c|}{$B \times 10^{27} / \mathrm{cm}^{3}$} \\
\hline & $2 \mathrm{~A}$ & $2 \mathrm{C}$ & $2 \mathrm{E}$ & $2 \mathrm{~F}$ & Most probable & & & $2 \mathrm{C}$ & $2 \mathrm{E}$ \\
\hline DMF & - & 1.09 & 1.05 & 1.05 & 1.06 & 2.51 & 12.6 & 2.33 & 2.32 \\
\hline $85 \mathrm{wt} \% \mathrm{EC} / \mathrm{W}$ & 0.95 & - & - & - & 0.95 & 2.25 & 10.1 & 0 & 0 \\
\hline $67 \mathrm{wt} \% \mathrm{HNO}_{3}$ & - & 1.29 & 1.29 & 1.30 & 1.29 & 3.06 & 18.5 & 3.17 & 2.69 \\
\hline $55 \mathrm{wt} \% \mathrm{HNO}_{3}$ & 1.06 & - & - & - & 1.06 & 2.51 & 12.6 & 0 & 0 \\
\hline
\end{tabular}
conformation parameter $\sigma$ and characteristic ratio $C_{\infty}$ of PAN in various solvents at $25^{\circ} \mathrm{C}$ 
(hydrodynamic approach), as expected.

The $A$ values for PAN in the EC/water mixture with $w_{\mathrm{e}}=85 \mathrm{wt} \%$ and $55 \mathrm{wt} \%$ aqueous nitric acid are 0.94 and $1.06 \times 10^{-8} \mathrm{~cm}$, respectively. These are comparable to 0.88 and $1.02 \times 10^{-8} \mathrm{~cm}$ evaluated for the AN/MA copolymer in two corresponding theta solvents $\left(\mathrm{EC} /\right.$ water mixture $\left(w_{\mathrm{e}}=82.5 \mathrm{wt}^{\mathrm{o}} \%\right)$ and 51 $\mathrm{wt} \%$ aqueous nitric acid).

The $A, \sigma$ and $C_{\infty}$ values in Table IV are significantly dependent on the nature of solvent: they are larger for better solvents and the $A$ value is maximum in $67 \mathrm{wt} \%$ aqueous nitric acid in which the $B$ value also attains a maximum. This was also observed in AN/MA copolymer solutions. ${ }^{1}$

The dependence of $A$ on solvent nature is quite remarkable for aqueous nitric acid with various $w_{\mathrm{n}}$. There may exist some specific interaction between nitric acid and the polymer chain. To gain a better understanding of the reasons for this, we investigated solvation phenomena.

Figure 11 shows the dependence of $n$ on the polymer concentrations of PAN and AN/MA copolymer in various solvents. In DMF and the EC/water mixture, $n$ was nearly always constant, irrespective of polymer concentration, but in aqueous nitric acid, it decreased linearly with an increase in concentration. $n_{0}$ was estimated as the intercept of the plot at infinite concentration in Figure 11. $n_{0}$ in organic solvents is relatively small: 0.4 for PAN and 0.3 for AN/MA copolymer. For PAN in organic solvents, solvation does not occur. $n_{0}$ increases with the concentration of nitric acid, suggesting that the degree of solvation is greater in much more concentrated nitric acid and the solvated molecule should not be water, but $\mathrm{HNO}_{3}, \mathrm{NO}_{3}{ }^{-}$or hydrated similar compounds. Interestingly, $n_{0}$ in aqueous nitric acid does not reduce to zero even in a theta solvent.

Figure 12 shows a plot of $A$ against $n_{0}$ for PAN and the AN/MA copolymer in various solvents. The data points for the $\mathrm{AN} / \mathrm{MA}$

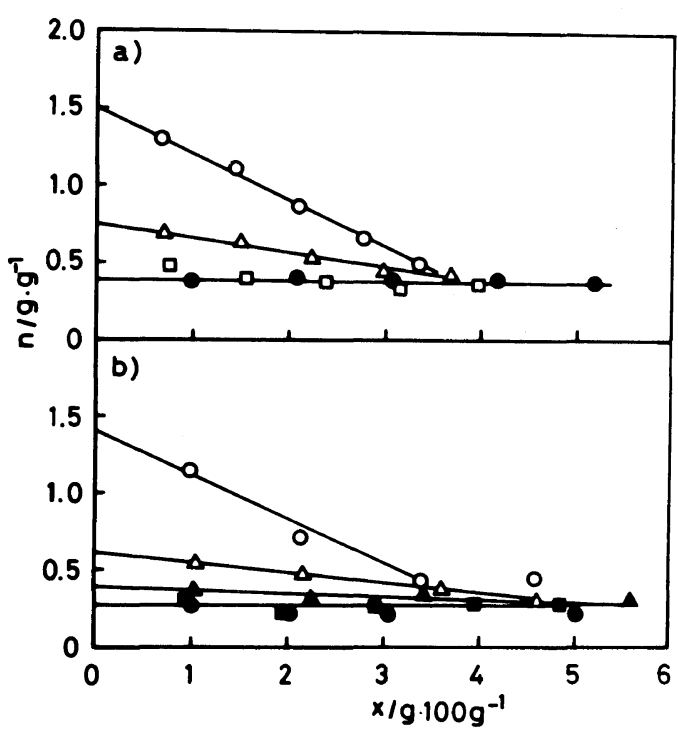

Figure 11. Plots of $\mathrm{n}$ versus concentration $x$ for PAN (a) and the AN/MA copolymer (b) at $25^{\circ} \mathrm{C}$ : $\bigcirc$, aqueous nitric acid $\left(w_{\mathrm{n}}=67 \mathrm{wt} \%\right) ; \triangle$, aqueous nitric acid $\left(w_{\mathrm{n}}=\right.$ $55 \mathrm{wt} \%) ; \boldsymbol{\Delta}$, aqueous nitric acid $\left(w_{\mathrm{n}}=51 \mathrm{wt} \%\right) ; \boldsymbol{O}$, DMF; $\square, \quad$ EC/water mixture $\left(w_{\mathrm{e}}=85 \mathrm{wt} \%\right)$; EC/water mixture $\left(w_{\mathrm{e}}=82.5 \mathrm{wt} \%\right)$.

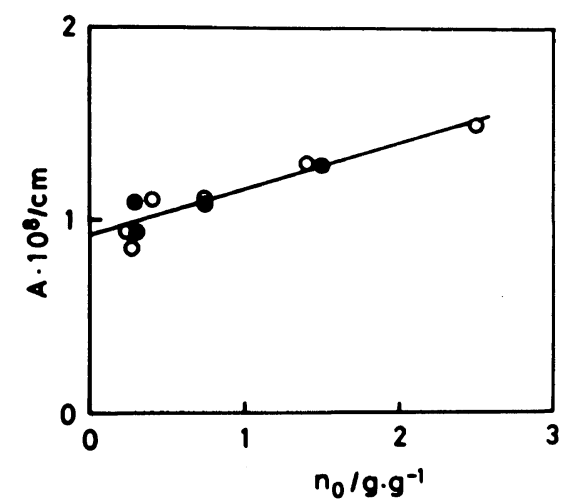

Figure 12. $n_{0}$ dependence of the short-range interaction parameter $A$ for PAN $(O)$ and the AN/MA copolymer (

copolymer were cited from a previous paper. ${ }^{1}$ The point of the largest $n_{0}$ corresponds to the AN/MA copolymer in $80 \mathrm{wt} \%$ nitric acid, extrapolated from the relations $n_{0}$ and $w_{\mathrm{n}} \leqq 67$ $\mathrm{wt}^{\mathrm{o}} \%$, through lack of direct data due to the strong corrosive properties of the acid. $A$ of both PAN and the AN/MA copolymer in- 


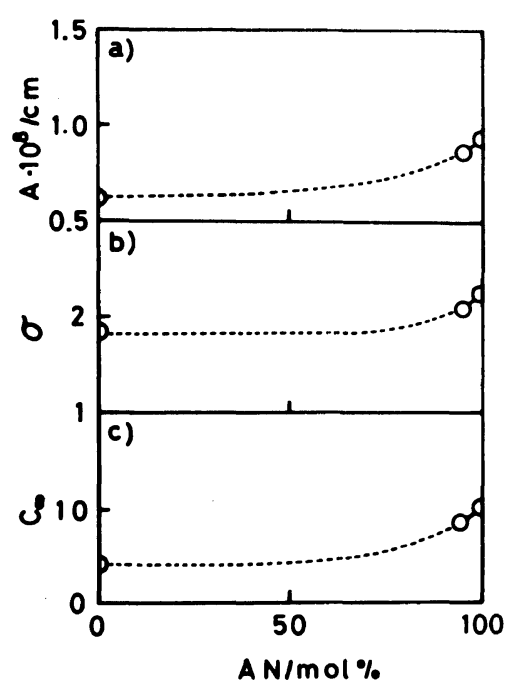

Figure 13. Effect of $\mathrm{AN}$ content in the polymer on the short range interaction parameter $A$, the conformation parameter $\sigma$ and the characteristic ratio $C_{\infty}$.

creases significantly with an increase in $n_{0}$. Similar conclusions have been reached by Kamide and Saito ${ }^{14}$ for the behavior of cellulose derivatives.

Figure 13 shows the dependence of $A, \sigma$ and $C_{\infty}$ on the AN content of PAN, the AN/MA copolymer and poly(methyl acrylate) (PMA). The former two polymers were dissolved in the EC/water mixture $w_{\mathrm{e}}=85$ and $82.5 \mathrm{wt} \%$ ) and latter in isoamyl acetate. The small variation in AN content in the AN/MA copolymer causes considerable variation in chain flexibility in the range where $\mathrm{AN}$ content is near to $100 \mathrm{~mol} \%$.

\section{APPENDIX}

$[\eta]_{20^{\circ} \mathrm{C}}^{\mathrm{DMF}}$ can be converted to $[\eta]$ of the DMF solution containing $\mathrm{LiCl}\left(0.1 \mathrm{wt}^{\mathrm{o}} \%\right)$ at $25^{\circ} \mathrm{C}$ $\left([\eta]_{25^{\circ} \mathrm{C}}^{\mathrm{DMF}(\mathrm{LiCl})}\right)$

$$
[\eta]_{25^{\circ} \mathrm{C}}^{\mathrm{DMF}(\mathrm{LiCl})}=[\eta]_{20^{\circ} \mathrm{C}}^{\mathrm{DMF}} \times 1.17 \times M_{w}{ }^{-0.022}
$$

The $M_{v}$ values in Table I of ref 9 were converted to those of $[\eta]_{25^{\circ} \mathrm{C}}^{\mathrm{DMF}(\mathrm{LiCl})}$, from which $M_{v}$ was recalculated using the MHS equation of the PAN solution in DMF, as indicated in Table II. Using the newly calculated $M_{v}$, we can reconstruct the MHS equations of PAN in $\mathrm{EC} /$ water $\left(w_{\mathrm{e}}=85 \mathrm{wt} \%\right)$ at 30 and $35^{\circ} \mathrm{C}$ as shown in ref 9 in the form,

$$
[\eta]=0.262 M_{v}^{0.502} \text { at } 30^{\circ} \mathrm{C}
$$

and

$$
[\eta]=0.201 M_{v}^{0.527} \text { at } 35^{\circ} \mathrm{C}
$$

The MHS equation (g) corresponding to $a=$ 0.5 can be extrapolated from the above two equations.

\section{REFERENCES}

1. K. Kamide, Y. Miyazaki, and H. Kobayashi, Polym. J., 14, 591 (1982).

2. R. L. Cleland and W. H. Stockmayer, J. Polym. Sci., 17, 473 (1955).

3. W. R. Krigbaum and A. M. Kotliar, J. Polym. Sci., 32, 323 (1958).

4. P. F. Onyon, J. Polym. Sci., 37, 315 (1959).

5. Y. Fujisaki and H. Kobayashi, Kobunshi Kagaku, 19, 73 (1962).

6. L. H. Peebles, J. Polym. Sci., A, 3, 361 (1965).

7. K. Kamide, H. Kobayashi, Y. Miyazaki, and C. Nakayama, Kobunshi Kagaku, 24, 679 (1967).

8. T. Shibukawa, M. Sone, A. Uchiki, and K. Iwahori, J. Polym. Sci., A-1, 6, 147 (1968).

9. K. Kamide, K. Fujii, and H. Kobayashi, Makromol. Chem., 117, 190 (1968).

10. K. Kamide and T. Terakawa, Makromol. Chem., 155, 25 (1972).

11. Y. Inoue and A. Nishioka, Polym. J., 3, 149 (1972).

12. K. Matsuzaki, T. Uryu, M. Okada, and H. Shiroki, J. Polym. Sci., A-1, 6, 1475 (1968).

13. E. R. Pike, W. R. M. Pomeroy, and J. M. Vaugham, J. Chem. Phys., 62, 3188 (1975).

14. K. Kamide and M. Saito, Eur. Polym. J., 20, 903 (1984).

15. A. Passynsky, Acta Physicochim., USSR, 22, 137 (1947).

16. K. Kamide, Y. Miyazaki, and T. Abe, Makromol. Chem., 177, 485 (1976).

17. R. E. Ewart, C. P. Roe, P. Debye, and J. R. McCartney, J. Chem. Phys., 14, 687 (1946).

18. Y. Fujisaki and H. Kobayashi, Kobunshi Kagaku, 19, 81 (1962).

19. H. Baumann, J. Polym. Sci., Polym. Lett., Ed., 3, 1069 (1965).

20. W. H. Stockmayer and M. Fixman, J. Polym. Sci., C, 1, 137 (1963).

21. K. Kamide and W. R. Moore, J. Polym. Sci., Polym. Lett. Ed., 2, 1029 (1964). 